\title{
LEARNING MEDIA DESIGN BASED ON TRADITIONAL GAME OF TUMBU-TUMBU BELANGA (T2B) ON SALT HYDROLYSIS TOPIC
}

\author{
Julhim S.Tangio ${ }^{1}$, Rusmiyati Patilima ${ }^{1}$, Jafar La Kilo ${ }^{1,2}$, Akram La Kilo ${ }^{1,2 *}$ \\ ${ }^{1}$ Program Studi Pendidikan Kimia, Fakultas Matematika dan Ilmu Pengetahuan Alam, Universitas Negeri \\ Gorontalo \\ ${ }^{2}$ Program Studi Kimia, Fakultas Matematika dan Ilmu Pengetahuan Alam, Universitas Negeri Gorontalo \\ *Corresponding author: akram@ung.ac.id
}

\begin{abstract}
This research aimed to test the validity of the feasibility of traditional game learning media on salt hydrolysis. This research was development research $(R \& D)$ with a qualitative descriptive approach. This research uses the ADDIE model development design, which consists of 5 (five) stages, namely (1) analysis, (2) design, (3) development, (4) implementation, and (5) evaluation. Data collection techniques in this study used a validation sheet for the assessment of the feasibility of tumbu-tumbu learning media. The tumbu-tumbu learning media validation wass assessed by 4 expert validators, namely 2 chemistry lecturers of Universitas Negeri Gorontalo material experts, 1 media expert lecturer, and 1 high school chemistry teacher. The results of the validation of Tumbu-Tumbu Belanga $\left(T_{2} B\right)$ learning media development obtained an average percentage of $89.40 \%$, which was categorized in very feasible criteria. Therefore, the $T_{2} B$ learning media are highly usable in the learning process of salt hydrolysis.
\end{abstract}

Keywords: Learning media; Traditional game; Tumbu-Tumbu Belanga; salt hydrolysis

\section{PENDAHULUAN}

Permainan tradisional di Gorontalo saat ini tidak dimainkan lagi oleh anak-anak. Anakanak hanya memainkan permainan modern seperti game yang terdapat pada handphone atau komputer. Permainan modern ini sangat mempengaruhi eksistensi permainan tradisional dan memudarkan nilai-nilai budaya di kalangan anak-anak. Bahkan dampak negatif lainnya adalah interaksi anak dan remaja bersama teman-temannya berkurang, semakin sempit/berkurang lokasi bermain, biaya permainan mahal, menumbuhkan sifat agresif dan individual, menurunkan kualitas belajar dan kesehatan tubuh serta mereduksi nilai-nilai kejujuran. Oleh karena itu, permainan tradisional perlu digalakkan kembali melalui sekolah sebagai media yang menarik dalam pembelajaran.

Beberapa permainan tradisional yang telah diuji dan digunakan untuk media pembelajaran adalah conglak (Sari, dkk., 2019), jamuran (Hartiwi, 2016), gaprek kempung (Wulandari, 2017), dan engklek (Lestariningrum, 2017). Semua media pembelajaran tersebut dapat meningkatkan hasil belajar siswa. Di Gorontalo, permainan tradisional yang dapat dijadikan sebagai media pembelajaran diantaranya adalah auta, bilubilulu, momotahu, tibagogi, dan TumbuTumbu Belanga $\left(\mathrm{T}_{2} \mathrm{~B}\right)$. Tiga permainan yang disebutkan di atas belum pernah diuji dan dilaporkan sebagai media pembelajaran. Media pembelajaran sebagai salah satu fasilitas yang sangat penting untuk mewujudkan tujuan pembelajaran. Oleh karena itu, dalam penelitian ini didesain media $\mathrm{T}_{2} \mathrm{~B}$ yang digunakan sebagai media pembelajaran pada topik hidrolisis garam pada Sekolah Menengah Atas (SMA).

Berdasarkan hasil pengamatan pada siswa SMA Negeri 1 Tapa bahwa tingkat ketuntasan belajar siswa pada topik hidrolisis garam masih rendah, yakni 53\% yang jauh di bawah Kriteria Ketuntasan Minimal (KKM). Hal tersebut diakibatkan oleh materi kimia yang sering dianggap sulit dan membosankan, penggunaan metode pembelajaran yang belum tepat, penerapan model pembelajaran kurang variatif, dan penggunaan media pembelajaran yang kurang sehingga membuat siswa cepat bosan dan jenuh terhadap materi yang 
diberikan. Fakta-fakta tersebut didukung oleh penelitian dari Febriani et al. (2018) dan Arsyad et al. (2016) yang melaporkan bahwa pemahaman siswa terhadap materi ini masih kurang karena adanya kesalahan konsep topik hidrolisis garam yang sering dialami siswa. Faktor-faktor yang menyebabkan siswa sulit mempelajari dan memahami topik hidrolisis garam dapat berasalan baik dari faktor internal maupun faktor eketernal. Pendisiplinan diri atau kebiasaan belajar adalah faktor internal yang sering dialami oleh siswa. Sementara, faktor sisanya adalah penjelasan, respon guru, dan kurangnya penggunaan media pembelajaran dalam proses pengajaran (Febriani, 2018). Selain itu, kebiasaan menghafal materi tanpa memahami apa yang dihafal mengakibatkan siswa rapuh dalam teori (La Kilo, 2017, Bait, dkk, 2018, Laliyo, 2010).

Salah satu media yang dapat diterapkan pada proses pembelajaran ialah media $\mathrm{T}_{2} \mathrm{~B}$. Berdasarkan hasil pengamatan yang telah dilakukan pada guru kimia SMA Negeri 1 Tapa bahwa $T_{2} B$ tidak pernah lagi dimainkan oleh siswa-siswa, mereka hanya mengetahui permainan tradisional $T_{2} B$ ini, namun siswa tidak tahu cara memainkannya. Siswa yang pernah memainkan permainan ini hanya berjumlah 6 siswa dari 65 siswa. $\mathrm{T}_{2} \mathrm{~B}$ merupakan permainan tradisional yang dimainkan secara berkelompok yang beranggotakan 4-5 orang. Namun, desain permainan $\mathrm{T}_{2} \mathrm{~B}$ (pada penelitian ini) akan dimainkan oleh dua orang siswa secara berpasangan untuk menghemat waktu dalam pembelajaran.

Pengorganisasian permainan $T_{2} B$ memerlukan model pembelajaran yang sesuai agar dapat mewujudkan pencapaian tujuan pembelajaran. Salah satu model yang dapat dipakai adalah Teams Games Tournament (TGT). Beberapa penelitian yang berhasil menerapkan model TGT adalah penelitian yang dilakukan oleh Tyasning \& Nurhayati (2012), Sani et al., (2015), Puji Astuti et al., (2017), Ibnu Sidik et al., (2016), Nuraeni et al., (2015), dan Rumape et al. (2020). TGT yang dilaporkan tersebut dilengkapi dengan LKPD, adobe flash, atau chem puzzle agar memudahkan pengorganisasian pembelajaran.
Penelitian ini bertujuan untuk mendesain media pembelajaran $\mathrm{T}_{2} \mathrm{~B}$ yang dapat diterapkan siswa pada topik hidrolisis garam. Media pembelajaran permainan tradisional $\mathrm{T}_{2} \mathrm{~B}$ didesain menggunakan aplikasi coreldraw dengan menampilkan tahap-tahap permainan $\mathrm{T}_{2} \mathrm{~B}$ dan materi hidrolisis garam, yang kemudian divalidasi oleh empat validator ahli.

\section{METODE}

\section{Jenis dan Prosedur Penelitian}

Jenis penelitian ini ialah deskriptif kualitatif terhadap media pembelajaran berbasis pemainan tradisional $\mathrm{T}_{2} \mathrm{~B}$ pada materi hidrolisis garam. Proses desain media pembelajaran berdasarkan model ADDIE yang terdiri dari lima tahap, yaitu tahap analysis (analisis), design (desain), developement (pengembangan), implementation (penerapan), dan evaluation (evaluasi). Penelitian ini dibatasi hingga tahap development.

\section{Instrumen dan Teknik Pengumpulan Data}

Media pembelajaran yang diukur validitasnya adalah media $\mathrm{T}_{2} \mathrm{~B}$, LKPD, dan RPP pada materi hidrolisis garam. Media tersebut diukur berdasarkan lembar validasi yang telah valid. Lembar validasi memuat aspek perwajahan, kelayakan isi, konstruksi, dan kelayakan bahasa (untuk $\mathrm{T}_{2} \mathrm{~B}$ ); rumusan tujuan pembelajaran, penyajian isi, penggunaan bahasa, dan waktu (untuk RPP); dan rumusan tujuan pembelajaran, isi yang disajikan, dan bahasa (untuk LKPD).

Penilaian validasi media tersebut diukur menurut skala Likert dengan skor minimal dan maksimal masing-masing 1 dan 5 . Kelima skor pilihan yang diberikan berturutturut dari rendah ke tinggi, masing-masing memiliki arti tidak valid, kurang valid, cukup valid, valid, dan sangat valid. Data-data yang dihasillkan dari instrumen ini merupakan informasi yang konstruktif guna memperbaiki media pembelajaran hingga dihasilkan media $\mathrm{T}_{2} \mathrm{~B}$ dan turunannya yang valid.

\section{Teknik Analisis Data}

Analisis data menggunakan analisis deskriptif kualitatif terhadap data hasil 
validasi media pembelajaran dari para validator ahli. Penetapan kategori validitas merujuk pada kriteria penilaian seperti yang dilakukan oleh Gonibala et al. (2019), yaitu: sangat valid (85-100\%), valid (69-84\%), cukup valid (53-68\%), kurang valid (37$67 \%$ ), dan tidak valid (21-36\%). Persentasi validitas diperoleh dengan rumus:

$$
\text { Persen validitas }=\frac{\sum \text { skor rerata }}{\text { skor maksimum }} \times 100 \%
$$

\section{HASIL DAN PEMBAHASAN}

Media pembelajaran yang telah diperoleh pada penelitian ini dikembangkan dengan model ADDIE. Hasil penelitian ini hanya membahas tahap validasi dan revisi desain produk pada tahap pengembangan. Dua tahap yang terakhir, yaitu implememntation dan evaluasi tidak dilakukan karena kondisi pandemi covid-19 yang tidak mendukung.

\section{Tahap Analisis}

Tahap analisis dilakukan terhadap empat (4) hal, yaitu analisis kompetensi dasar dan indikator, analisis peserta didik, analisis media, dan analisis konsep. Analsisi ini sebagai dasar dalam merancang dan mengembangan media pembelajaran $T_{2} B$.

\section{Analisis Kompetensi Dasar dan Indikator}

Kompetensi dasar dan indikator yang termuat dalam Rencana Pelaksanaan Pembelajaran (RPP) sesuai dengan kurikulum 2013. Kompetensi ini meliputi aspek pengetahuan, sikap, dan keterampilan yang harus dikuasai oleh siswa setelah mempelajari topik hidrolisis garam. Indikator-indikator topik ini dituliskan dari materi yang mudah ke sampai materi yang sulit agar memudahkan siswa mempelajarinya. Oleh karena itu, kompetensi ini dapat dijadikan sebagai dasar rancangan dan pengembangan media $\mathrm{T}_{2} \mathrm{~B}$.

\section{Analisis Peserta Didik}

Karakteristik dan kebutuhan peserta didik sangat menentukan pengembangan media pembelajaran tumbu-tumbu belanga. Hasil analisis yang diperoleh: 1) peserta didik lebih senang terhadap guru yang menggunakan media dalam proses pembelajar, 2) peserta didik lebih suka pembelajaran yang diselingi dengan permainan, 3) peserta didik kelas XI SMA 1 Tapa cenderung melakukan pembelajaran dengan format ceramah, diskusi, dan pemberian tugas.

\section{Analisis Media}

Analisis media dilakukan sebagai dasar dalam mengembangkan media pembelajaran $\mathrm{T}_{2} \mathrm{~B}$. Adapun hasil analisis yang diperoleh yakni 1) guru jarang menggunakan media dalam kegiatan pembelajaran, 2) media power point merupakan salah satu media yang pernah digunakan guru dalam kegiatan pembelajaran, dan 3) pembelajaran berbasis permainan tradisional belum pernah dilakukan oleh guru. Beberapa peneliti telah mempublikasikan bahwa media yang digunakan pada materi hidrolisis garam diantaranya adalah truth and dare (Susanti, 2019), buletin buku saku (Retno, 2015), adobe flash (Catur, 2015), happy chemist (Kharolinasari, 2020) dan software ispring suite (Novi, 2020) dan game edukasi (Purnama, 2018).

Penyajian materi yang menarik dalam media tersebut dapat memudahkan dan mengarahkan siswa mempelajari materi hidrolissi garam. Media power point juga dapat memudahkan siswa mencatat poin-poin penting dalam hidrolisis garam, namun penyajian yang kurang menarik dan penerapan model pembelajaran ceramah dapat membuat siswa sulit memahami materi yang disajikan. Media $\mathrm{T}_{2} \mathrm{~B}$ memiliki kekhasan lokal yang mudah terterima dan dimainkan oleh siswa, bahkan diduga dapat memotivasi mahasiswa untuk mempelajari materi. Permainan yang dimainkan secara pasangan ini dapat memantik kompetitif siswa.

\section{Analisis Konsep}

Langkah utama yang dilakukan dalam analisis konsep adalah mengidentifikasi topik utama yang diajarkan secara sistematis menggunakan produk yang dikembangkan. Kompetensi dasar dan indikator dalam topik hidrolisis garam (sesuai kurkulum 2013) merupakan. Topik tersebut dibuat dalam ringkasan materi yang diintegrasikan ke dalam media pembelajaran permainan $T_{2} B$. Konsep yang dipelajari pada hidrolisis garam terdiri 
dari sifat-sifat garam terhidrolisis, jenis reaksi hidrolisis, dan derajat keasaman $(p \mathrm{H})$ dari larutan garam yang terhidrolisis. Konsep hidrolisis garam merupakan suatu tipe reaksi ion-ion dengan air yang bergantung pada sifat ion apakah mengalami hidolisis atau tidak; 1) ion negatif dari asam kuat dan ion positif dari basa kuat tidak mengalami hidrolisis dan 2) sebaliknya ion positifnegatif dari asam lemah dan ion positif dari basa lemah mengalami hidrolisis. Oleh karena itu, materi ini dapat dipahami jika siswa paham dengan dua konsep utama, yaitu asam basa dan reaksi kesetimbangan, reversibel.

\section{Tahap Perancangan}

Tahapan perancangan yang dilakukan dalam pembuatan media meliputi tiga langkah yaitu:

\section{Menentukan Desain Media}

Rancangan media dilakukan dengan merancang secara umum media permainan tumbu-tumbu belanga yang dikembangkan. Media ini merupakan alat bantu untuk guru dan peserta didik dalam pembelajaran hidrolisis garam. Materi hidolisis garam berisi konsep dan perhitungan sehingga memnutuhkan media pembelajaran yang menarik untuk memotivasi siswa. Isi dalam media ini adalah pendahuluan (identitas), materi hidrolisis garam, lagu $\mathrm{T}_{2} \mathrm{~B}$, dan petunjuk permainan. Karena $T_{2} B$ dimainkan secara tradisional maka desain media harus mempertimbangkan juga efektivitas waktu dengan memperhatikan setiap tahap dalam permainan. Akibatnya, $\mathrm{T}_{2} \mathrm{~B}$ yang didesain ini termodifikasi dari $\mathrm{T}_{2} \mathrm{~B}$ asli.

\section{Membuat Rancangan Media}

Setelah mengetahui langkah-langkah permainan tumbu-tumbu dan menentukan tema media permainan tradisional tumbutumbu, maka langkah selanjutnya yaitu membuat rancangan media dengan menggunakan software choreldraw. Tahap perancangan media ini terdiri dari beberapa tahapan yaitu: 1) Pemilihan format, pemilihan format dilakukan untuk menentukan desain media pembelajaran permainan tumbu-tumbu yang dirancang menggunakan corel draw. 2) Materi, pemilihan materi yang digunakan dalam desain media pembelajaran permainan tumbu-tumbu belanga berdasarkan pada karakteristik materi yang lebih dominan kepada teori atau materi yang bersifat konseptual. 3) RPP, rencana pelaksanann pembelajaran yang digunakan pada penelitian ini mengacu pada format PERMENDIKBUD RI Nomor 22 Tahun 2016 yang memuat identitas sekolah dan mata pelajaran, kompetensi inti dan dasar, indikator, tujuan, materi, metode/model, sumber belajar, langkah-langkah, alokasi waktu, dan penilaian hasil pembelajaran. Model pembelajaran pada penelitian pengembangan media pembelajaran permainan tradisional tumbu-tumbu belangan menggunakan Teams Games Tournament, yang telah dicantumkan dalam RPP. 4) Media, media pembelajaran diadopsi dari permainan tradisional Gorontalo tumbu-tumbu belanga. Permainan ini telah dimodifikasi berdasarkan kebutuhan dalam proses pembelajaran.

\section{Tahap Pengembangan}

Pengembangan media tumbu-tumbu belanga dikukan melalui tiga tahp yang saling berkaitan satu dengan yang lainnya. Ketiga tahap tersebut adalah pembuatan produk, validasi, dan revisi produk.

\section{Pembuatan Produk}

Pengembangan media pembelajaran dibuat dalam bentuk gambar atau sketsa menurut langkah-langkah permainan tumbutumbu belanga. Pengembangan diwawali dengan merancang langkah-langkah permainan tumbu-tumbu belanga yang disesuaikan dengan tujuan pembelajaran materi hidrolisis garam untuk proses pembelajaran. Kemudian medianya didesain dalam bentuk gambar sketsa. Produk akhir yang dihasilkan berbentuk gambar atau sketsa langkah-langkah media tumbu-tumbu. Terakhir, media dapat dikembangkan dalam bentuk video permainan tumbu-tumbu dengan menggunakan aplikasi Corel Draw. Hal tersebut dilakukan unutk memudahkan media pembeljaran ini dipelajari baik oleh peserta didik maupun masyarakat luas.

\section{Validasi}


Validasi media tumbu-tumbu belanga meliputi validasi ahli materi dan validasi ahli media yang merupakan prasyarat utama sebelum media ini diujicobakan pada peserta didik. Sementara, penilaian terhadap kelayakan media tumbu-tumbu ini diberikan pada empat orang ahli sebagai validator. Tim validator terdiri atas 3 dosen UNG (2 dosen ahli materi kimia dan 1 dosen ahli media) dan 1 guru Kimia SMA. Berikut hasil penilaian oleh validator ahli.

\section{Hasil Validasi Media Pembelajaran}

Hasil penilaian ahli terhadap media pembelajaran $T_{2} B$ disajikan dalam Tabel 1.

Tabel 1. Hasil Validitas Media Pembelajaran

\begin{tabular}{|c|c|c|c|c|c|c|c|}
\hline \multirow{2}{*}{$\begin{array}{l}\text { Aspek yang } \\
\text { Dinilai }\end{array}$} & \multicolumn{4}{|c|}{ Skor Penilaian Validator } & \multirow{2}{*}{$\bar{X}$} & \multirow{2}{*}{$\%$} & \multirow{2}{*}{$\begin{array}{l}\text { Kasederhana dan menarik dapat memudahkan } \\
\text { gosiswa memahami materi dan bahkan }\end{array}$} \\
\hline & 1 & 2 & 3 & 4 & & & \\
\hline Perwajahan & 4,50 & 4,00 & 5,00 & 3,00 & 4,13 & 82,5 & Whereduksi miskonsepsi siswa. Oleh karena itu \\
\hline $\begin{array}{l}\text { Kelayakan } \\
\text { Isi }\end{array}$ & 4,80 & 5,00 & 5,00 & 4,00 & 4,70 & 94,0 & $\begin{array}{l}\text { Spnedia dalam pembelajaran ini dilengkapi } \\
\text { dengan LKPD yang telah divalidasi yang }\end{array}$ \\
\hline Konstruksi & 4,40 & 5,00 & 5,00 & 4,20 & 4,65 & 93,0 & Shihemaut secara lengap materi dan soal latihan \\
\hline Kelayakan & 4,60 & 4,00 & 5,00 & 4,00 & 4,40 & 88,0 & S\&an evaluasi. \\
\hline
\end{tabular}

$\begin{array}{cccccccc}\text { Bahasa } & & & & & & & \\ \text { Rata-rata } & 4,57 & 4,50 & 5,00 & 3,80 & 4,47 & 89,4 & \text { SV Adanya media ini diharapkan }\end{array}$ pengunaannya dapat membuat siswa belajar

Berdasarkan Tabel 1 penilaian ahli terhadap media pembelajaran, keseluruhan media pembelajaran memiliki persentase skor rata-rata $89,40 \%$ (sangat valid). Nilai ini berada di atas nilai rata kriteria minimal kevalidan (69\%-84\%) media pembelajaran. Konstruksi dan dan kelayakan ini mencapai nilai di atas 90 yang mennjukkan bahwa topik hirolisis garam telah representatif dan terantang dengan baik antara satu topik dengan topik lainnya.

Perwajahan media sangat menentukan ketertarikan atau minat baca siswa untuk membaca lebih lanjut isi materi dari suatu media. Perwajahan dapat berupa penggunaan font (jenis, ukuran dan spasi), tata letak, kejelasan gambar dan ilustrasi, serta kejelasan rancangan tampilan. Jika salah satu cacat dari komponen perwajahan tersebut maka media yang disajikan dapat menurunkan minat belajar siswa. Tampilan media yang menarik dapat meningkatkan minat belajar siswa (Ditama, 2015). Indikator kelayakan isi dalam penelitian ini adalah kesesuaian (KI, KD, dan kondisi siswa), kejelasan dan keakuratan, kebermanfaatan, peningkatan wawasan, dan kebenaran substansi materi. Penyajian isi materi yang tepat adalah sesuai dengan tujuan pembelajaran, taraf kemampuan siswa, dapat memotivasi siswa dan mengaktifkan pikiran serta aktivitas siswa (Suryani, 2014). Penyajian yang dikemukan ini sesuai dengan konstruksi dalam penelitian ini, yaitu kejelasan tujuan dan langkah-langkah media permainan tumbu-tumbu belanga, dapat memotivasi dan menarik perhatian peserta didik, dan interaktif, serta memiliki informasi yang lengkap.

Bahasa media yang baik harus memuat keterbacaan dan memenuhi kaidah bahasa Indonesia yang baik dan benar serta penggunaaan bahasa yang jelas dan singkat. Materi sulit yang ditulis dengan bahasa yang Kałederhana dan menarik dapat memudahkan siswa memahami materi dan bahkan mandiri meskipun tanpa kehadiran guru atau pengajar. Meskipun demikian, kehadiran guru sangat diharapkan untuk melakukan bimbingan pada siswa dalam menemukan makna dari konsep yang dipelajari. Ischak, Odja, La Kilo, \& La Kilo (2020) melaporkan bahwa bimbingan guru dapat menambah peningkatan hasil belajar peserta didik pada materi asam basa.

\section{Hasil Validasi RPP}

Hasil penilaian ahli terhadap RPP disajikan dalam Tabel 2.

Tabel 2. Hasil Validitas RPP

\begin{tabular}{ccccccc}
$\begin{array}{c}\text { Aspek yang } \\
\text { Dinilai }\end{array}$ & \multicolumn{3}{c}{ Skor Penilaian } & & $\%$ & Kategori \\
\cline { 2 - 4 } & 1 & 2 & 3 & $\bar{X}$ & & \\
\hline $\begin{array}{c}\text { Tujuan } \\
\begin{array}{c}\text { Pembela- } \\
\text { jaran } \\
\text { Isi yang }\end{array}\end{array}$ & 4,80 & 5,00 & 5,00 & 4,93 & 98,60 & $\mathrm{SV}$ \\
$\begin{array}{c}\text { Disajikan } \\
\text { Bahasa }\end{array}$ & 5,00 & 5,00 & 5,00 & 5,00 & 100 & $\mathrm{SV}$ \\
\hline
\end{tabular}

Vol. 5, No. 1, June 2021 (27-35) 


\begin{tabular}{rrrrrrr}
\hline Waktu & 5,00 & 4,00 & 5,00 & 4,67 & 93,40 & SV Revisi
\end{tabular}

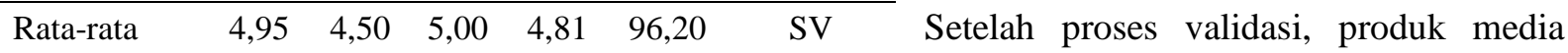
pembelajaran permainan tumbu-tumbu

Berdasarkan penilaian ahli terhadap RPP (Tabel 2), skor rata-rata RPP adalah memiliki persentase $96,20 \%$ dengan kategori sangat valid (SV). Nilai ini jauh di atas nilai rata-rata minimal untuk RPP (69\%-84\%). Tujuan, penyajian isi, bahasa, dan waktu dalam RPP ini masing-masing memiliki skor di atas $93 \%$. Hal tersebut menunjukkan bahwa RPP yang dikembangkan memenuhi model pembelajaran Teams Games Tournament berbasis permainan tradisional tumbu-tumbu belanga.

\section{Hasil Validasi LKPD}

Hasil validasi ahli terhadap LKPD disajikan dalam Tabel 3.

Tabel 3. Hasil Analisis Validitas LKPD

\begin{tabular}{|c|c|c|c|c|c|c|}
\hline \multirow{2}{*}{$\begin{array}{c}\text { Aspek } \\
\text { yang } \\
\text { Dinilai }\end{array}$} & \multicolumn{3}{|c|}{$\begin{array}{c}\text { Skor Penilaian } \\
\text { Validator }\end{array}$} & \multirow[b]{2}{*}{$\bar{X}$} & \multirow[t]{2}{*}{$\%$} & \multirow{2}{*}{$\begin{array}{l}\text { Kate- } \\
\text { gori }\end{array}$} \\
\hline & 1 & 2 & 3 & & & \\
\hline $\begin{array}{l}\text { Isi yang } \\
\text { Disajikan }\end{array}$ & 4,50 & 5,00 & 5,00 & 4,83 & 96,6 & SV \\
\hline Bahasa & 4,40 & 4,00 & 5,00 & 4,47 & 89,4 & SV \\
\hline Rata-rata & 4,45 & 4,50 & 5,00 & 4,65 & 93,0 & SV \\
\hline
\end{tabular}

Berdasarkan Tabel 3 penilaian ahli terhadap LKPD, skor rata-rata LKPD adalah $93,00 \%$, berkategori sangat valid (SV) dan jauh berada di atas skor rata-rata minimal kelayakan LKPD. Isi dan bahasa yang digunakan pada LKPD ini memiliki nilai rata-rata masing-masing adalah $96,6 \%$ dan $89,4 \%$. Isi LKPD pada topik hidrolisis garam dimulai dari konsep yang sederhana sebelum konsep yang sulit/kompleks yang diuraikan dengan bahasa yang jelas dan mudah dipahami oleh peserta didik agar tidak terjadi miskonsepsi. Sihaloho dkk. (2021) melaporkan bahwa peserta didik mengalami miskonsepsi karena ketidakpahaman mereka terhadap konsep kimia yang sederhana. Alhamdulilah, LKPD telah memenuhi kriteria model pembelajaran TGT berbasis permainan $\mathrm{T}_{2} \mathrm{~B}$ yang dapat digunakan dalam kegiatan pembelajaran. belanga yang dihasilkan dibuat sedemikian rupa agar memenuhi kebutuhan dan menarik bagi peserta didik. Oleh karena itu, komentar dan saran baik ahli materi maupun ahli media sangat diperlukan dan dilaksanan dalam merivisi media ini hingga menjadi produk akhir. Revisi dilakukan berulang-ulang sehingga mendapatkan hasil media pembelajaran permainan tumbu-tumbu seperti pada Gambar 1.

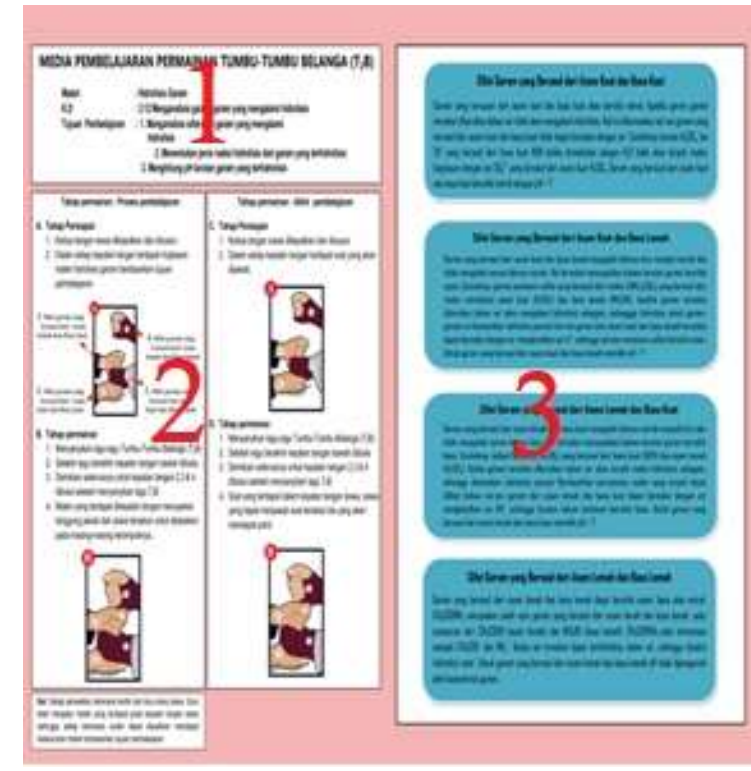

\section{Gambar 1. Produk Permainan Tumbu-Tumbu Belanga ; 1) identitas materi pembelajaran, 2) tahap permainan T2B, 3) materi.}

Desain tersebut terdiri dari tiga domain utama, yaitu identitas materi pembelajaran, tahap permainan $\mathrm{T}_{2} \mathrm{~B}$, dan materi pembelajaran. Domain tahap permainan $\mathrm{T}_{2} \mathrm{~B}$ diiringi dengan lagu tradisional Gorontalo, yaitu:

\author{
Tumbu-tumbu \\ Li Maso'i \\ So'i-so'i leke \\ Leke kambu-kambu \\ Kambula kapa \\ Bu'ade tibawa
}


Lagu tersebut dinyayikan selama permainan menurut tahap-tahap yang dilukiskan dalam Gambar 2.

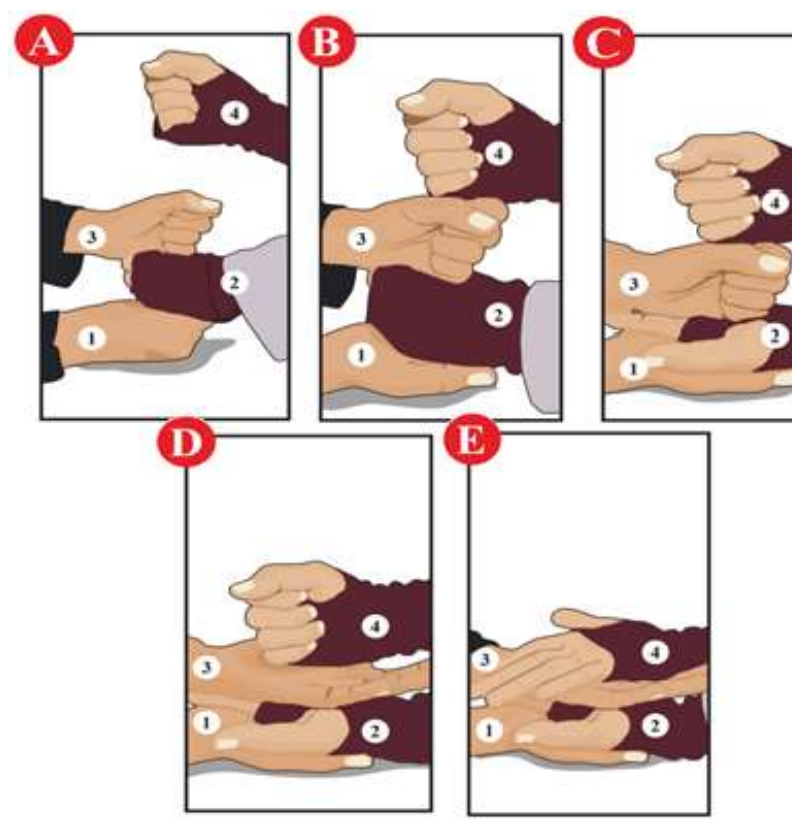

Gambar 2. Tahap-tahap permainan Tumbu-

Tumbu (T2B): (A) Tahap awal untuk permainan $\mathrm{T}_{2} \mathrm{~B}$, kedua tangan siswa dikepalkan dan disusun. Dalam setiap kepalan tangan terdapat soal yang akan dijawab. (B) Kepalan tangan dibuka diawalai dari kepalan tangan paling bawah setelah menyanyikan lagu tumbu-tumbu , kemudian menjawab soal nomor 1. (C) Kepalan tangan kedua dibuka setelah menyanyikan lagu tumbu-tumbu dan menjawab soal nomor 2. (D) Kepalan tangan ketiga dibuka setelah menyanyikan lagu tumbu-tumbu dan menjawab soal nomor 3. (E) Tahap akhir kepalan tangan keempat dibuka setelah menyanyikan lagu tumbutumbu dan menjawab soal nomor 4 .

\section{SIMPULAN DAN SARAN}

Media pembelajaran berbasis permainan tradisional tumbu-tumbu pada materi hidrolisis garam telah valid baik validitas konstruk maupun isi. Validitas ini berkategori sangat baik yang menunjukkan permainan ini layak diujikan pada siswa dalam pembelajaran.
Media ini perlu dikembangkan pada tahap penerapan dan evaluasi untuk mengetahui keefektifanmedia ini dalam pembelajaran di kelas.

\section{DAFTAR PUSTAKA}

[1] C. K. Sari, A. Muslihatun, L. Cahyaningtyas, R. N. L. H. Khaimmudin, R. N. Fijatullah, and E. U. Nisa', "Pemanfaatan permainan tradisional untuk media pembelajaran: Congklak bilangan sebagai inovasi pembelajaran matematika sekolah dasar," Transform. J. Pengabdi. Masy., 2019 , doi: 10.20414/transformasi.v15i1.915.

[2] D. Hartiwi and D. A. Zahraini, "Peningkatan Kemampuan Berbicara melalui Permainan Tradisional Jamuran pada Anak Kelompok Bermain di PAUD Taman Belia Candi Tahun Pelajaran 2015/2016," PAUDIA J. Penelit. dalam Bid. Pendidik. anak usia dini, vol. 5, no. 2, Oct. 2016, doi: 10.26877/paudia.v5i2.1182.

[3] F. Wulandari, W. Wahjoedi, and S. H. Utomo, "Permainan Tradisional 'Gaprek Kempung' Sebagai Media Pembelajaran Pada Mata Pelajaran Ekonomi Kelas Vii," J. Pendidik. Teor. Penelitian, dan Pengemb., vol. 2, no. 3, pp. 331-340, 2017.

[4] A. Lestariningrum and M. Crie, "Analisis Pengembangan Kecerdasan Logis Matematis Anak Usia 5-6 Tahun Menggunakan," J. Pendidik. USIA DINI Vol. 11 Ed. 2, Novemb. 2017, pp. 215-225, 2017.

[5] G. Febriani, S. Marfu'ah, and R. Joharmawan, "Identifikasi Konsep Sukar, Kesalahan Konsep, dan FaktorFaktor Penyebab Kesulitan Belajar Hidrolisis Garam Siswa Salah Satu SMA Blitar," J-PEK (Jurnal Pembelajaran Kim., 2018, doi: 10.17977/um026v3i22018p035.

[6] M. A. M. Arsyad, M. Sihaloho, and A. La Kilo, "Analisis miskonsepsi pada konsep hidrolisis garam siswa kelas XI SMAN 1 Telaga," Jambura J. Educ. Chem., vol. 11, no. 2, pp. 190-195, 2016. 
[7] A. La Kilo, "Solusi rumus derajat keasaman reaksi asam basa pada larutan penyangga dengan metode mol awal (rumus akram)," PATEN, vol. 8, no. $1065,2017$.

[8] D. J. Bait, S. Duengo, and A. La Kilo, "Pengaruh model pembelajaran simayang tipe II terhadap peningkatan kemampuan representasi kimia siswa kelas X pada materi larutan elektrolit dan nonelektrolit di SMA Terpadu Wira Bhakti Gorontalo," Jambura J. Educ. Chem., vol. 13, no. 2, pp. 157163, 2018.

[9] L. A. R. Laliyo, M. Kau, J. La Kilo, and A. La Kilo, "Kemampuan siswa memecahkan masalah hukum-hukum dasar kimia melalui pembelajaran inkuiri terbimbing," AR-RAZI J. Ilm., vol. 8 , no. 1 , pp. $1-8$, Apr. 2020, doi: 10.29406/ar-r.v8i1.1875.

[10] D. M. Tyasning and N. D. Nurhayati, "Penerapan Model Pembelajaran TGT (Teams Games Tournaments) Dilengkapi LKS untuk Meningkatkan Aktivitas dan Hasil Belajar Materi Minyak Bumi pada Siswa Kelas X-4 SMA Batik 1 Surakarta Tahun Pelajaran 2011/ 2012," J. Pendidik. Kim. Univ. Sebel. Maret, 2012.

[11] M. Sani, N. Afifah, and E. Afniyanti, "Pengaruh Model Pembelajaran Kooperatif Tipe Team Games Tournament (Tgt) Terhadap Hasil Belajar Biologi Siswa Kelas X Sma N 1 Kepenuhan Kabupaten Rokan Hulu Tahun Pembelajaran 2014 / 2015," J. Ilm. Mhs. FKIP Prodi Biol., vol. 1, no. 1, pp. 1-3, 2015.

[12] S. Puji Astuti, B. Mulyani, and B. Utami, "Penerapan Model Pembelajaran Teams Games Tournament (TGT) untuk Meningkatkan Minat Belajar dan Prestasi Belajar Siswa pada Materi Kelarutan dan Hasil Kali Kelarutan Kelas XI MIA 3 SMA Al Islam 1 Surakarta Tahun Ajaran 2015/2016," Pendidik. Kim., vol. 6, pp. 109-118, 2017.

[13] T. Ibnu Sidik, M. Masykuri, and B. Mulyani, "PEnerapan Model Pembelajaran Teams Games
Tournament (TGT) Dilengkapi Adobe Flash Untuk Meningkatkan Aktivitas dan Prestasi Belajar Siswa pada Materi Kelarutan dan Hasil Kali Kelarutan Kelas Xi IPA di SMA N 2 Boyolali Tahun Pelajaran 2014/2015," Pendidik. Kim., vol. 5, pp. 41-45, 2016.

[14] R. Nuraeni, A. Nugroho Catur Saputro, and T. Redjeki, "Penerapan Model Pembelajaran Kooperatif Tipe Teams Games Tournament (TGT) Dilengkapi Chem Puzzle untuk Meningkatkan Kreativitas dan Prestasi Belajar Siswa pada Materi Hidrokarbon Kelas X Semester 2 SMA Negeri 1 Kartasura Tahun Pelajaran 2013/2014," Pendidik. Kim., vol. 4, pp. 44-52, 2015.

[15] O. Rumape, N. Christopel, J. La Kilo, and A. La Kilo, "Penerapan Pembelajaran Teams Games Tournament (TGT) Dilengkapi Kartu Nama dari Tata Nama Senyawa Kimia untuk Meningkatkan Hasil Belajar Siswa," J. Pendidik. Kim. Indones., vol. 4, no. 1, 2020.

[16] A. Gonibala, M. Pikoli, and A. La Kilo, "Validitas perangkat pembelajaran materi ikatan kimia berbasis model pembelajaran pemaknaan untuk melatihkan sensitivitas moral siswa SMA," Jambura J. Educ. Chem., vol. 1, no. 1, pp. 1-6, Feb. 2019, doi: 10.34312/jjec.v1i1.2067.

[17] A. Susanti, "Penerapan Model Pembelajaran Inkuiri Terbimbing Dengan Berbantuan Media Truth and Dare Untuk Meningkatkan Aktivitas dan Hasil Belajar Siswa Pada Materi Hidrolisis Garam," UNIMED, 2019.

[18] A. T. P. Retno, S. Saputro, and B. Utami, "Pengembangan media pembelajaran buletin dalam bentuk buku saku berbasis hirarki konsep untuk pembelajaran kimia kelas XI materi hidrolisis garam," J. Pendidik. Kim., vol. 4, no. 2, pp. 74-81, 2015.

[19] A. N. Catur Saputro, V. Ditama, and S. Saputro, "Pengembangan Multimedia Interaktif dengan Menggunakan Program Adobe Flash untuk Pembelajaran Kimia Materi Hidrolisis Garam SMA Kelas XI," J. Pendidik. Kim. Univ. Sebel. Maret, vol. 4, no. 2, 
2015.

[20] R. Kharolinasari, E. B. Susatyo, and S. Sarwana, "Pengembangan Media Pembelajaran Interaktif Happy Chemist pada Materi Hidrolisis untuk Mengukur Pemahaman Konsep Siswa," J. Inov. Pendidik. Kim., vol. 14, no. 1, pp. 2547-2560, 2020.

[21] I. Novi, "Desain dan Uji Coba LKPD Interaktif Berbantuan Software Ispring Suite 8 dengan Pendekatan Scaffolding pada Materi Hidrolisis Garam," Universitas Islam Negeri Sultan Syarif Kasim Riau, 2020.

[22] N. Purnama, "Pengembangan Media Pembelajaran Game Edukasi Pada Materi Hidrolisis Garam," SKRIPSI Jur. Kim. MIPA UM, 2018.

[23] V. Ditama and S. Saputro, "Pengembangan Multimedia Interaktif dengan Menggunakan Program Adobe Flash untuk Pembelajaran Kimia," $J$.
Pendidik. Kim., vol. 4, no. 2, 2015.

[24] D. I. Suryani, T. Suhery, and A. R. Ibrahim, "Pengembangan Modul Kimia Reaksi Reduksi Oksidasi Kelas X SMA," J. Penelit. Pendidik. Kim. Kaji. Has. Penelit. Pendidik. Kim., vol. 1, no. 1, pp. 18-28, 2014.

[25] N. I. Ischak, E. A. Odja, J. La Kilo, and A. La Kilo, "Pengaruh Keterampilan Proses Sains Melalui Model Inkuiri Terbimbing terhadap Hasil Belajar Siswa pada Materi Larutan Asam Basa," Hydrog. J. Kependidikan Kim., vol. 8, no. 2, pp. 58-66, 2020.

[26] M. Sihaloho, S. S. Hadis, A. K. Kilo, and A. La Kilo, "Diagnosa Miskonsepsi Siswa SMA Negeri 1 Telaga Gorontalo pada Materi Termokimia," Jambura J. Educ. Chem., vol. 3, no. 1, pp. 7-13, 2021. 